\title{
Do we need yet another way to classify atrial fibrillation?
}

\author{
Dawn S. Hui, MD, and Richard Lee, MD, MBA
}

\author{
From the Center for Comprehensive Cardiovascular Care, Saint Louis University, St Louis, Mo. \\ Disclosures: Authors have nothing to disclose with regard to commercial support. \\ Received for publication June 15, 2017; accepted for publication June 19, 2017; available ahead of print July 25 , \\ 2017. \\ Address for reprints: Richard Lee, MD, MBA, Center for Comprehensive Cardiovascular Care, Saint Louis \\ University, 3635 Vista Ave, DT 13F, St Louis, MO 63110 (E-mail: rlee@slu.edu). \\ J Thorac Cardiovasc Surg 2017;154:1267-8 \\ $0022-5223 / \$ 36.00$ \\ Copyright (C) 2017 by The American Association for Thoracic Surgery \\ http://dx.doi.org/10.1016/j.jtcvs.2017.06.047
}

In this issue, the Journal presents an important study by Filardo and colleagues ${ }^{1}$ examining postoperative atrial fibrillation (POAF) after isolated coronary artery bypass grafting. Two assertions are made in this article: (1) the Society for Thoracic Surgeons (STS) cardiac database misses nearly 10,000 patients with POAF annually; and (2) these missed patients carry an unrecognized significant increase in 30-day mortality. Determining whether these conclusions can be drawn from their data requires parsing the complexities of defining and studying POAF.

In their study, Filardo and colleagues ${ }^{1}$ define atrial fibrillation (AF) as "any episode via continuous monitoring and documented by physician in a chart." This differs not only from the STS definition as AF "requiring treatment" but also from the Heart Rhythm Society definition of "any arrhythmia that has the ECG characteristics of AF and lasts sufficiently long for a 12-lead ECG to be recorded, or at least 30 seconds on a rhythm strip." ${ }^{2}$ Two questions arise: (1) What is the goal of creating this third definition? (2) Are there actionable findings based on this third definition? Filardo and colleagues ${ }^{1}$ suggest that there is a rationale for this redefinition, as suggested by their findings of an associated increase in 30-day mortality when comparing patients with untreated POAF with those with treated POAF. The clinical reasons underlying the absence of POAF treatment, however, which may also have an impact on mortality, were not further explored in the study. This makes it quite difficult to determine the significance of this new definition.

Because the study population came from highly esteemed, high-quality heart programs, simple neglect to treat POAF can reasonably be discarded, leaving 3 other plausible scenarios: (1) AF that self-terminated before treatment; (2) AF that, without treatment, was slow or rate controlled; or (3) patient contraindications to POAF treatment. As Gillinov and associates ${ }^{3}$ have shown, short-term mortality is similar between rate and rhythm control strategies; the second group thus should not explain the increased 30-day mortality. The third group may be the key to putting untreated POAF into context. Although Filardo and colleagues ${ }^{1}$ adjusted for STS predicted risk of operative mortality, they did not indicate whether baseline characteristic

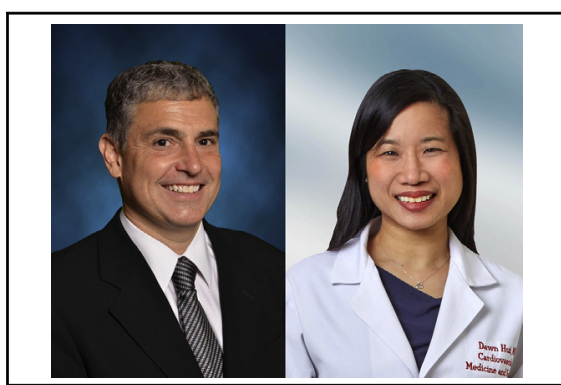

Richard Lee, MD, MBA (left), and Dawn S. Hui, MD (right)

\section{Central Message}

"It has long been an axiom of mine that the little things are infinitely the most important."Sir Arthur Conan Doyle (said by Sherlock Holmes in "A Case of Identity," 1891).

See Article page 1260 .

differences across groups were significant. In reviewing the data, there are several noticeable differences: patients with untreated POAF had higher rates of myocardial infarction within 24 hours, congestive heart failure, previous coronary artery bypass grafting, and preoperative intra-aortic balloon pump support (Table 1). It is possible that this constellation of preoperative characteristics may have resulted in postoperative states such as multiple organ failure, hemodynamic status, or other clinical scenario contraindicating AF treatment. Thus lack of treatment of POAF may simply be a proxy for other postoperative complications that are associated with higher 30-day mortality risk and that are not captured by the STS predicted risk of operative mortality. If this is the case, the focus should then be less on treatment versus lack of treatment of POAF and more on the underlying factors for lack of treatment.

There are also peripheral issues of defining "treatment." As the authors of the Contemporary Analysis of Perioperative Cardiovascular Surgical-Care AF registry study noted, one limitation in studying POAF is that "postoperative medical therapy cannot be specifically attributed to PAOF, versus other indications (eg, $\beta$-blockers for CAD vs POAF)." 4 The definition of Filardo and colleagues ${ }^{1}$ also relies on physician documentation. These subtleties may explain the interinstitutional variation found by Filardo and colleagues, ${ }^{1}$ and it would remain an issue even if the STS definition of AF were adjusted to what they have proposed.

In the 1970s, we classified AF as intermittent and continuous. In 2006, we changed the definition to include, 
TABLE 1. Selected variables from the study of Filardo and colleagues ${ }^{1}$

\begin{tabular}{|c|c|c|c|}
\hline \multirow[b]{2}{*}{ Characteristic } & \multicolumn{2}{|c|}{ POAF } & \multirow[b]{2}{*}{$\begin{array}{c}\text { No } \\
\text { POAF }\end{array}$} \\
\hline & $\begin{array}{c}\text { AF not in } \\
\text { STS data } \\
\text { (untreated AF) }\end{array}$ & $\begin{array}{c}\text { AF in } \\
\text { STS data } \\
\text { (treated AF) }\end{array}$ & \\
\hline $\begin{array}{l}\text { Myocardial infarction }<24 \mathrm{~h} \\
\text { before CABG }\end{array}$ & 5.2 & 3.1 & 2.9 \\
\hline Congestive heart failure & 30.4 & 26 & 21.9 \\
\hline Previous CABG & 6.6 & 4.5 & 4.6 \\
\hline $\begin{array}{l}\text { Preoperative intra-aortic } \\
\text { balloon pump }\end{array}$ & 18.8 & 15.5 & 10.7 \\
\hline
\end{tabular}

$P O A F$, Postoperative atrial fibrillation; $A F$, atrial fibrillation; $S T S$, Society of Thoracic Surgeons; $C A B G$, coronary artery bypass grafting.

paroxysmal, persistent, and permanent, ${ }^{5}$ then added long-standing persistent in $2014 .{ }^{6}$ We now have an STS definition, as well as a Heart Rhythm Society definition that differs. This relatively small series does not provide enough evidence to justify the addition of yet another definition.

\section{References}

1. Filardo G, Pollock BD, da Graca B, Phan TK, Sass DM, Ailawadi G, et al. Underestimation of the incidence of new-onset post-coronary artery bypass grafting atrial fibrillation and its impact on 30-day mortality. J Thorac Cardiovasc Surg. 2017;154:1260-6.

2. Calkins H, Kuck KH, Cappato R, Brugada J, Camm AJ, Chen SA, et al. Heart Rhythm Society Task Force on Catheter and Surgical Ablation of Atrial Fibrillation. 2012 HRS/EHRA/ECAS expert consensus statement on catheter and surgical ablation of atrial fibrillation: recommendations for patient selection, procedural techniques, patient management and follow-up, definitions, endpoints, and research trial design: a report of the Heart Rhythm Society (HRS) Task Force on Catheter and Surgical Ablation of Atrial Fibrillation. Developed in partnership with the European Heart Rhythm Association (EHRA), a registered branch of the European Society of Cardiology (ESC) and the European Cardiac Arrhythmia Society (ECAS); and in collaboration with the American College of Cardiology (ACC), American Heart Association (AHA), the Asia Pacific Heart Rhythm Society (APHRS), and the Society of Thoracic Surgeons (STS). Endorsed by the governing bodies of the American College of Cardiology Foundation, the American Heart Association, the European Cardiac Arrhythmia Society, the European Heart Rhythm Association, the Society of Thoracic Surgeons, the Asia Pacific Heart Rhythm Society, and the Heart Rhythm Society. Heart Rhythm. 2012;9: 632-96.e21.

3. Gillinov AM, Bagiella E, Moskowitz AJ, Raiten JM, Groh MA, Bowdish ME, et al; CTSN. Rate control versus rhythm control for atrial fibrillation after cardiac surgery. N Engl J Med. 2016;374:1911-21.

4. Steinberg BA, Zhao Y, Hernandez AF, Fullerton DA, Thomas KL, Mills R, et al. Management of postoperative atrial fibrillation and subsequent outcomes in contemporary patients undergoing cardiac surgery: Insights from the Society of Thoracic Surgeons CAPS-Care atrial fibrillation registry. Clin Cardiol. 2014;37: 7-13.

5. Fuster V, Rydén LE, Cannom DS, Crijns HJ, Curtis AB, Ellenbogen KA, et al. American College of Cardiology/American Heart Association Task Force on Practice Guidelines; European Society of Cardiology Committee for Practice Guidelines; European Heart Rhythm Association; Heart Rhythm Society. ACC/AHA/ ESC 2006 Guidelines for the Management of Patients with Atrial Fibrillation: a report of the American College of Cardiology/American Heart Association Task Force on Practice Guidelines and the European Society of Cardiology Committee for Practice Guidelines (Writing Committee to Revise the 2001 Guidelines for the Management of Patients With Atrial Fibrillation): developed in collaboration with the European Heart Rhythm Association and the Heart Rhythm Society. Circulation. 2006;114:e257-354.

6. January CT, Wann LS, Alpert JS, Calkins H, Cigarroa JE, Cleveland JC Jr, et al; ACC/AHA Task Force Members. 2014 AHA/ACC/HRS guideline for the management of patients with atrial fibrillation: executive summary: a report of the American College of Cardiology/American Heart Association Task Force on practice guidelines and the Heart Rhythm Society. Circulation. 2014;130: 2071-104. 